ENSAIO

Recebido em: 09/03/2017

Aceito em: $02 / 02 / 2018$

\title{
Informação e Memória: aproximações teóricas e conceituais
}

\section{Information and Memory: theoretical and conceptual approaches}

\author{
Ana Pricila Celedonio da SILVA (priceledonio@gmail.com)* \\ Lidia Eugenia CAVALCANTE (cavalcantelidiaeugenia@gmail.com)** \\ Jefferson Veras NUNES (jefferson.veras@yahoo.com.br)*** \\ * Mestranda em Ciência da Informação pelo Programa de Pós-Graduação em Ciência da Informação da \\ Universidade Federal do Ceará (PPGCI/UFC) \\ ** Doutora em Educação pela Universidade Federal do Ceará. Professora do Programa de Pós- \\ Graduação em Ciência da Informação da UFC (PPGCI/UFC). \\ *** Doutor em Ciência da Informação pelo programa de Pós-Graduação em Ciência da Informação da \\ Universidade Estadual Paulista (UNESP); Professor do Programa de Pós-Graduação em Ciência da \\ Informação da UFC (PPGCI/UFC).
}

\begin{abstract}
Resumo
Objetiva apresentar, por meio de revisão de literatura, os conceitos e as relações existentes entre os termos Informação e Memória na Ciência da Informação (CI), a partir dos paradigmas Físico, Cognitivo E Social de Rafael Capurro (2003) e dos estudos ligados ao tema Memória, baseados em autores como: Halbwachs (1990); Nora (1993); Le Goff (2003) e Bergson (1999), por meio dos quais foi possível identificar os enlaces existentes entre os dois termos, através das concepções material, cognitiva e coletiva da Memória. A reflexão no âmbito da CI e da Memória, teve como elementos norteadores, principalmente, os paradigmas Custodial e Pós-Custodial apresentados por Malheiro e Ribeiro (2011) Nesses paradigmas, a relação entre a CI e a Memória se evidencia desde as antigas práticas custodiais ligadas aos campos da Biblioteconomia, Arquivologia e Museologia, e a criação da Documentação, campo que antecedeu a CI. Nesse sentido, reflete-se que a Memória transita pelo campo da Informação e áreas correlatas, desde muito tempo, e se apresenta hoje como objeto de estudo da área através de olhar informacional sobre a mesma.

Palavras-chave: Informação e Memória. Paradigmas da Ciência da Informação. Elementos norteadores da Informação e da Memória.
\end{abstract}

\begin{abstract}
It aims to present, through a literature review, the concepts and relations between the terms Information and Memory in Information Science (IS), based on the Physical, Cognitive and Social paradigms of Rafael Capurro (2003) and the studies related to Memory theme, based on authors such as: Halbwachs (1990); Nora (1993); Le Goff (2003) and Bergson (1999), through which it was possible to identify the existing links between the two terms, through the material, cognitive and collective conceptions of Memory. The reflection in the scope of the IS and the Memory, had as guiding elements, mainly, the Custodial and Post-Custodial paradigms presented by Malheiro and Ribeiro (2011). In these paradigms, the relationship between SI and Memory is evident from the old custodial practices related to the fields of Library Science, Archival Science and Museology, and the creation of Documentation, a field that preceded CI. In this sense, it is reflected that Memory travels through the field of Information and related areas, since a long time, and presents itself today as object of study of the area through an informational look at it.

Keywords: Information and Memory. Paradigms of Information Science. Guiding Elements of Information and Memory.
\end{abstract}

v. 23, n. $52,2018$. p. $95-106$

ISSN 1518-2924 


\section{INTRODUÇÃO}

0 estudo tem o intuito de articular discussões referentes à memória e à informação e, ainda, discutir este tema, abrangente e complexo que é a memória, no campo específico da Ciência da Informação (CI). Outrossim, demanda, inicialmente, buscar compreender qual o lugar destinado à memória nas discussões epistemológicas da área. Para identificar essas relações, recorremos aos paradigmas que envolvem a definição do conceito de informação e do próprio campo da CI.

Os paradigmas são utilizados como norteadores das práticas científicas. Capurro (2003) realizou a sistematização da definição de informação através de três paradigmas, a saber: o Paradigma Físico, Paradigma Cognitivo e o Paradigma Social. Neste estudo, articulamos as definições de informação ligadas a cada um desses paradigmas às concepções de memória, onde podemos perceber a existência de relações conceituais entre os dois termos, através da compreensão cognitiva, material e coletiva imbricadas às concepções do conceito de memória.

Recorremos, ainda, a outras perspectivas paradigmáticas envolvendo a $\mathrm{CI}$, onde encontramos nos paradigmas Custodial e Pós-Custodial de Malheiro e Ribeiro (2011), a perspectiva da memória advinda como herança para a CI, das práticas custodiais ligadas às antigas instituições-memória, como as bibliotecas, arquivos e museus. No trabalho desses autores, observamos que, no processo de transição para o paradigma Pós-Custodial, as áreas da Ciência da Informação, Biblioteconomia, Arquivologia e Museologia têm suas práticas ressignificadas, onde a guarda e processamento de informação são realizadas não mais pela finalidade da custódia, mas para o acesso. E, nesses processos de transição, é possível perceber que a memória permanece ainda atrelada a essas áreas, mas de forma ressignificada pelo olhar informacional da CI.

Dessa forma, o texto ora apresentado configura-se como uma revisão de literatura, focada especialmente em dois aspectos, o primeiro deles envolve os enlaces conceituais entre memória e informação, através, principalmente, de estudos realizados no âmbito da $\mathrm{CI}$ e, também, de estudos ligados ao campo da História. 0 segundo enfoque se direciona ao modo como a memória está presente no contexto histórico da CI e em suas discussões epistemológicas. Para essa análise, utilizamos como ponto de discussão, principalmente, os paradigmas Custodial e Pós-Custodial propostos por Malheiro e Ribeiro (2011).

\section{ENLACES CONCEITUAIS ENTRE INFORMAÇÃO E MEMÓRIA}

A informação tem sido ponto central em discussões que envolvem os âmbitos social, científico, econômico e político caracterizando a "Era da Informação" ou "Sociedade da Informação". Do ponto de vista de Castells (2008), a Sociedade da Informação tem como principal característica a forte presença e influência das Tecnologias de Informação e de Comunicação (TIC). A informação seria, dessa forma, a matéria-prima desse tempo e sociedade, sendo intrínseca a todos os processos que perpassam a vida dos indivíduos.

Por outro lado, a memória, que já foi cultuada pelos gregos antigos como a deusa Mnemosine (LE GOFF, 2003), vem sendo ressignificada pelos momentos de fluidez (BAUMAN, 2001) em que vivemos. Enquanto a informação está tão fortemente relacionada ao nosso cotidiano, a memória tem passado por um processo de "esquecimento", como afirma Pierre Nora (1993).

Consideramos, inicialmente, o termo informação, tendo em vista o caráter amplo do mesmo. A sua definição tem sido tarefa complexa e vem sendo buscada, há várias décadas, pelas mais diversas áreas científicas. Partimos aqui, de discussões que ocorrem no âmbito da CI que, segundo alguns estudiosos, têm como objeto de estudo a informação, suas dinâmicas e seus fluxos.

Etimologicamente, o termo informação possui duas origens, uma latina e outra grega. Na primeira delas, latina, vem do verbo informare, que significa dar forma, criar, e, no grego, pelos termos morphe, morfo, e eidos, que significam, respectivamente, forma, ideia, 
aquilo que se vê. Esse termo possui como uma de suas características as muitas faces de entendimento e definições que lhe são dadas. Wurman (1991, p. 42) chama atenção para este aspecto acerca da polissemia do termo, quando reflete que,

A palavra "informação" sempre foi ambígua e literalmente empregada para definir diversos conceitos. Os dicionários registram que a palavra tem sua raiz no latim informare [...] A definição mais comum é "a ação de informar, formação ou moldagem da mente ou do caráter, treinamento, instrução, ensinamento, comunicação de conhecimento instrutivo.

Capurro e Hjorland (2007) afirmam que o conceito de informação, cotidianamente é usado no sentido de conhecimento comunicado. Na sistematização da conceituação de informação na CI, realizada por Capurro (2003), o autor relaciona o conceito do termo a três principais paradigmas, o Físico, o Cognitivo e o Social. 0 primeiro deles teve como marco a Teoria Matemática da Comunicação de Claude Shannon e Warren Weaver (1949). Dessa teoria surge o primeiro conceito de informação incorporado pela Ciência da Informação, o qual, "implica numa analogia entre a veiculação física de um sinal e a transmissão de uma mensagem, cujos aspectos semânticos e pragmáticos intimamente relacionados ao uso diário do termo informação são explicitamente descartados por Shannon." (CAPURRRO, 2003, p.7)

Segundo Araújo (2012, p. 146) nessa primeira teoria acolhida pela CI, o significado de informação pode ser compreendido "como um fenômeno objetivo, com existência independente dos sujeitos e dos contextos, algo possível de ser transmitido tal como é de um ponto a outro num processo de comunicação."

Como contraponto à concepção física da informação, surge uma outra acepção para a mesma, que parte da proposta do sentido cognitivo da informação de Brookes (1977), a qual Capurro (2003) identifica no Paradigma Cognitivo. Nesse momento, a informação passa a ser compreendida como algo com capacidade de modificar os estados cognitivos dos sujeitos, e passa-se a dar, "especial atenção às maneiras como os indivíduos percebem seus estados de lacuna cognitiva e as estratégias utilizadas por eles para buscar e usar as informações de que necessitam." (ARAÚJO, 2012, p. 148)

Assim como no Paradigma Físico, que foi influenciado fortemente pela Teoria Matemática de Shannon e Weaver (1949), o Paradigma Cognitivo de Brookes (1977) possui como teoria influenciadora, a teoria de Karl Popper, conhecida como os "Três Mundos de Popper". Sobre esta Capurro (2003, p. 8-9) destaca que,

A ontologia popperiana distingue três mundos, a saber: o físico, o da consciência ou dos estados psíquicos, e o do conteúdo intelectual de livros e documentos, em particular o das teorias científicas. Popper fala do „terceiro mundo“ como um mundo de objetos inteligíveis ou também de conhecimento sem sujeito cognoscente.

No entendimento de Capurro (2003), no Paradigma Cognitivo considera-se a informação, "ou como algo separado do usuário localizado em um mundo numênico, ou de ver o usuário, se não exclusivamente como sujeito cognoscente, em primeiro lugar como tal, deixando de lado os condicionamentos sociais e materiais do existir humano." (CAPURRO, 2003, p. 9)

A terceira abordagem acerca da informação é apreciada por Capurro (2003) no Paradigma Social, que emerge da necessidade de se repensar a compreensão do processo informacional. Nesse paradigma, é a natureza social e coletiva da informação que é levada em consideração, o seu enraizamento em um determinado contexto e, ainda, o caráter ativo do sujeito. Esse paradigma surge devido à limitação existente no Paradigma Cognitivo, em que se considera o sujeito cognoscente muitas vezes dissociado do contexto social. 0 
Paradigma Social, seria uma integração do ponto de vista "individualista e isolacionista do Paradigma Cognitivo dentro de um contexto social no qual diferentes comunidades desenvolvem seus critérios de seleção e relevância. " (CAPURRO, 2003, p. 11)

González de Gómez (2009) considera a conceituação da informação na Ciência da Informação através de duas abordagens, uma fisicalista e outra mentalista. A abordagem fisicalista estaria relacionada àquela que Capurro (2003) chamou de Paradigma Físico. Nessa abordagem, é dada ênfase ao caráter material e físico da informação, como na Teoria Matemática de Shannon e Weaver (1949), e na informação-como-coisa de Buckland (1991).

A abordagem mentalista surge na década de 1980 como contraponto ao modelo fisicalista e material da informação, através de estudos de Belkin (1984) e Belkin, Oddy e Brooks (1982), os quais propõem a concepção cognitiva da informação. Nessa concepção, "[...] encontrarão sustentação as enunciações acerca da intangibilidade da informação, ao deslocar o objeto dos estudos da recuperação de informação, de uma primeira ênfase nas fontes de informação e nos sistemas, em direção aos usuários. " (GONZÁLEZ DE GÓMEZ, 2009, p.118)

Nessas abordagens da informação apresentadas por González de Gómez (2009), vemos que se assemelha ao entendimento físico e cognitivo proposto nos dois primeiros paradigmas de Capurro (2003). o que nos faz refletir que o entendimento acerca da informação transita entre abordagens que, ou se excluem, ou se complementam. Podemos ver a existência de duas principais abordagens - de um lado, uma física, material, e, do lado oposto, a abordagem cognitiva e mentalista. Entretanto, observamos, que pela insuficiência de se conseguir contemplar a dinâmica informacional, torna-se necessária uma abordagem que contemple a dinâmica e os fluxos pertencentes aos processos informacionais em relação ao contexto, o que podemos ver através do Paradigma Social.

Passamos, agora, a definição do termo memória. Os caminhos para a conceituação desse termo não são mais ou menos simples do que os percorridos na definição do termo informação. Esta, também, é uma tarefa complexa, e que perpassa vários entendimentos, visto que assim como a informação, a memória está relacionada a outros campos do saber, como a Neurociência, a Educação, a Psicologia, a História, dentre outros.

0 uso cotidiano do termo memória evoca principalmente seu significado como a capacidade de nosso cérebro de recordar fatos, eventos e informações. Esse sentido é compreendido como a "propriedade de conservar certas informações, remete-nos em primeiro lugar a um conjunto de funções psíquicas, graças às quais o homem pode atualizar impressões ou informações passadas, ou que ele representa como passadas. " (LE GOFF, 2003, p. 419)

Ainda em uma visão cognitiva da memória, trazemos também a concepção de Bergson (2010, p.266), de que a memória "tem por função primeira evocar todas as percepções passadas análogas a uma percepção presente, recordar-nos o que precedeu e o que seguiu, sugerindo-nos assim a decisão mais útil". A memória, segundo esse pensamento, seria a responsável por "guardar" nossas percepções, aquilo que vivenciamos, e que se juntam a todo momento às percepções vividas no presente. Dessa forma, é possível dizer que realizamos constantemente, por meio dessa nossa capacidade cognitiva, um encontro entre passado e presente, encontro esse, que influencia e cria o futuro.

Observamos, nessa primeira concepção apresentada sobre a memória, numa perspectiva cognitiva, uma semelhança com a visão da informação como fenômeno cognitivo, discutida por Brookes (1977) e Belkin (1984), a qual observamos no Paradigma Cognitivo de Capurro (2003). A memória, enquanto faculdade mental, cognitiva, retém informações, ou seja, a memória como processo mental estaria a priori na informação, pois conseguimos produzir informações, porque somos capazes antes, de "armazená-las" e "processá-las" em nossa mente.

Outra concepção de memória, muito presente em nosso cotidiano, é a da memória que registramos ou armazenamos por meio de recursos eletrônicos para guardar dados, 
informações, arquivos etc., sejam eles de natureza sonora, imagéticos e textuais. Esses recursos, de caráter físico e digital, são considerados por Oliveira e Rodrigues (2011, p. 216) como uma "memória adicional possibilitada por recursos tecnológicos, ou um procedimento técnico que permite sua fixação e facilita sua recuperação. " Entretanto, há milênios, materiais como papiros, pergaminhos, papel, dentre outros, são utilizados como suportes para os registros do conhecimento e da memória.

Le Goff (2003) considera essa concepção acerca da memória, como "memória artificial", aquela que é realizada e fixada por meio de suportes e mecanismos, como a escrita, e que hoje se realiza também através de computadores e demais técnicas e instrumentos. Podemos, então, perceber a memória em um significado material, físico, uma perspectiva semelhante à informação como fenômeno físico, como nos apresentou Capurro (2003).

A materialização da informação evidenciada nos documentos físicos é também a materialização da memória - a memória social, intelectual e científica da humanidade. Nessa discussão, Paul Otlet (1934) no Traité de Documentation discute a importância da organização do conhecimento humano, por meio da qual seria possível preservar a memória intelectual da sociedade.

A memória pode ser vista também sob o ponto de vista do seu caráter social, como aquela apresentada por Halbwachs (1990) que a compreende como memória coletiva. Segundo o autor, a memória se apresenta sob dois entendimentos, um individual e outro coletivo. A memória individual é aquela que o indivíduo carrega consigo, entretanto, essa mesma memória não deixa de perpassar pelos grupos, de se tornar lembranças em comum. 0 autor reflete ainda que,

\footnotetext{
No mais, se a memória coletiva tira sua força e sua duração do fato de ter por suporte um conjunto de homens, não obstante eles são indivíduos que se lembram, enquanto membros do grupo. Dessa massa de lembranças comuns, e que se apóiam uma sobre a outra, não são as mesmas que aparecerão com mais intensidade para cada um deles. Diríamos voluntariamente que cada memória individual é um ponto de vista sobre a memória coletiva, que este ponto de vista muda conforme o lugar que ali eu ocupo, e que este lugar mesmo muda segundo as relações que mantenho com outros meios. (HALBWACHS, 1990, p. 33)
}

Nesse sentido, podemos compreender que a memória, seja ela definida na esfera individual ou coletiva, não deixa de, em algum momento, fazer parte de um grupo. Assim sendo, a memória seria sempre coletiva. A recordação nunca está isolada de participantes, ela acontece em conjunto, porque essa é a sua natureza. Reforçamos esta afirmativa por meio do que Halbwachs (1990) reflete logo a seguir.

\footnotetext{
Mas nossas lembranças permanecem coletivas, e elas nos são lembradas pelos outros, mesmo que se trate de acontecimentos nos quais só nós estivemos envolvidos, e com objetos que só nós vimos. 'E porque, em realidade, nunca estamos sós. Não é necessário que outros homens estejam lá, que se distingam materialmente de nós: porque temos sempre conosco e em nós uma quantidade de pessoas que não se confundem. (HALBWACHS, 1990, p. 33)
}

Comungando com o pensamento de Halbwachs (1990), Nora (1993) identifica que a memória coletiva é o que fica no passado, no vivido dos grupos, ou o que os grupos fazem do passado. Nora (1993, p. 9) define a memória de forma bastante poética, fala da mesma como fenômeno sagrado, vivido em um eterno presente, cheio de recordações, de lembranças que emergem de "um grupo que ela une, o que quer dizer que há tantas memórias quantos 
grupos existem; que ela é por natureza, múltipla e desacelerada, coletiva, plural e individualizada."

A acepção que vemos na percepção da memória coletiva de Halbwachs (1990) e de Nora (1993) é comum a que Capurro (2003) apresenta quando esse autor argumenta que a informação é um fenômeno social. Assim, A informação e a memória seriam produtos sociais e que emergem de grupos.

Há, ainda, mais uma aproximção a ser feita ao termo memória, que é apresentada por Candau (2012) ao relacionar memória e identidade. Para Candau (2012) memória e identidade possuem uma relação intrínseca, em que a primeira tem grande importância na construção da identidade do sujeito e do coletivo. Sem suas lembranças o sujeito não se reconhece, não existe. Esse autor afirma que,

A memória, ao mesmo tempo em que nos modela, é também por nós modelada, isso resume perfeitamente a dialética da memória e da identidade que se conjugam e nutrem mutuamente. [...] os laços fundamentais entre memória e identidade e sobre o fato de que é a memória, faculdade primeira, que alimenta a identidade. (CANDAU, 2012, p. 16)

Michel Pollak (1992) também reflete sobre o binômio identidade e memória, segundo esse autor, a memória seria um elemento singular em relação a identidade de um indivíduo, sendo ainda "um fator extremamente importante do sentimento de continuidade e de coerência de uma pessoa ou de um grupo em sua reconstrução de si. " (POLLAK, 1992, p. 204)

Podemos, então, observar que a memória e a informação (vistas à luz das reflexões epistemológicas da CI) possuem como ponto em comum justamente as conceituações Física, Cognitiva e Social que são congregadas nos paradigmas de Capurro (2003).

Na Figura 1, realizamos uma síntese para ilustrar as relações entre informação e memória, a partir desses paradigmas.

\section{Relações conceituais entre Informação e Memória}

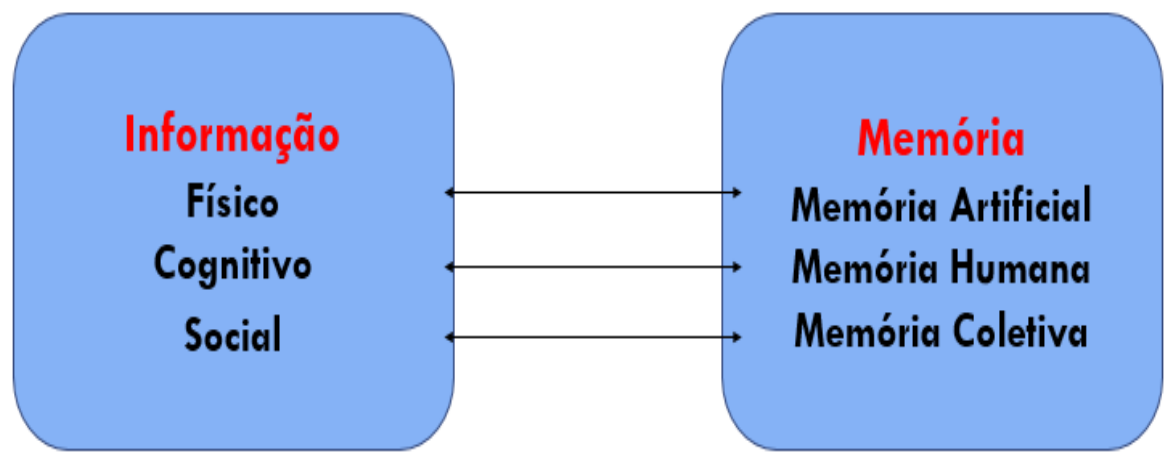

Figura 1 - Relações conceituais entre informação e memória.

Fonte: elaborada pelos autores.

Ao fazermos relação entre informação e memória podemos, então, pressupor que a $\mathrm{CI}$, como campo que estuda a informação, deve dedicar esforços para estudos que explorem esse caráter informacional da memória. Assim, buscamos apresentar indicações na literatura da área, de como a memória pode ser percebida no contexto histórico da CI. 


\section{CIÊNCIA DA INFORMAÇÃO E MEMÓRIA: da herança custodial à abordagem pós- custodial}

Estudos apontam a Ciência da Informação como uma ciência pós-moderna, humana, social e de caráter interdisciplinar. Robredo (2003, p.5) define a CI como a disciplina "que investiga as propriedades e o comportamento da informação, as forças que regem o fluxo da informação e os meios de processamento da informação para um máximo de acessibilidades e uso."

A consolidação da CI como campo científico ocorre na década de 1960, estando seu surgimento relacionado ao campo da Documentação, que surge no início do século XX, através das contribuições de Paul Otlet e Henri La Fontaine. Assim, a CI emerge em meio ao crescimento da produção dos registros de informação e a necessidade de facilitar o acesso ao conhecimento acumulado. A partir daí, surgem também estudos acerca das práticas documentais, assim como novas concepções sobre o documento e a informação. (ROBREDO, 2003)

Nos estudos de Malheiro e Ribeiro (2011) acerca dos "Paradigmas serviços e mediações em Ciência da Informação", os autores atrelam a história da Ciência da Informação, da Documentação, da Biblioteconomia, da Arquivologia e da Museologia à transição de dois paradigmas, o Custodial e o Pós-Custodial. 0 primeiro deles, é referente às práticas custodiais de origem milenares nas bibliotecas, arquivos e museus, em que o foco de suas atividades encontrava-se na guarda e custódia dos acervos. E o segundo, o póscustodial, indicados pelos autores como um paradigma emergente, e que se refere a nova abordagem dessas práticas, que passam a ter como foco não a guarda, mas o processamento e o acesso aos conteúdos informacionais.

No Quadro 1, apresentamos os principais traços relacionados ao Paradigma Custodial (patrimonialista, historicista e tecnicista), evidenciados por Malheiro e Ribeiro (2011).

Quadro 1 - Traços Essenciais do Paradigmas Custodial.

\section{PARADIGMA CUSTODIAL}

Sobrevalorização da custódia ou guarda, conservação e restauro do suporte, como função basilar da atividade profissional de arquivistas e bibliotecários;

Identificação do serviço/missão custodial e público de Arquivo e Biblioteca, com a preservação da cultura "erudita", "letrada" ou "intelectualizada" (as artes, as letras e as ciências), em antinomia mais ou menos explícita, com a cultura popular, "de massas" e de entretenimento;

Enfatização da memória como fonte legitimadora do Estado-Nação e da cultura como reforço identitário do mesmo Estado e respectivo Povo, sob a égide de ideologias de viés nacionalista;

Importância crescente do acesso ao "conteúdo", através de instrumentos de pesquisa (guias, inventários, catálogos e índices) dos documentos e do aprofundamento dos modelos de classificação e indexação, derivados do importante legado tecnicista e normativo dos belgas Paul Otlet e Henri La Fontaine, com impacto na área da documentação científica e técnica, possibilitando a multiplicação de Centros e Serviços de Documentação/Informação, menos vocacionados para a custódia e mais para a disseminação informacional.

Fonte: Malheiro e Ribeiro (2011, p. 34-35)

Observando os traços identificados pelos autores anteriormente apresentados para o primeiro paradigma, vemos que as práticas das instituições como bibliotecas e arquivos 
estavam voltadas para um fazer focado na guarda do suporte e da preservação da cultura e da memória. Na perspectiva de Malheiro e Ribeiro (2011), na Antiguidade, a finalidade da preservação da memória esteve imbricada nesse fazer custodial de arquivos, bibliotecas e museus. As sociedades antigas viam na guarda dos registros de seu conhecimento, uma forma de perpetuação da sua memória, e também como forma de demonstração de poder. Nos períodos seguintes, Idade Média, Renascimento e após a Revolução Francesa, a memória continua ligada ao sentido de identidade social e cultural das sociedades. Com a queda do regime monárquico, o Estado vê na preservação da memória uma das funções das bibliotecas e arquivos públicos, reforçando a identidade da nação e de seu povo. (MALHEIRO; RIBEIRO, 2011)

Ainda sobre as características elencadas para o Paradigma Custodial, observamos que, a transição para o Paradigma Pós-Custodial já começa a dar indícios quando novas técnicas, advindas da catalogação e da classificação, com Otlet e La Fontaine, passam a ter sua preocupação voltada à forma de processamento e acesso ao conteúdo informacional dos documentos. 0 que demonstra que a transição não ocorre por ruptura, mas de forma gradual, onde novas perspectivas de atuação de bibliotecários, arquivistas e documentalistas vão cada vez mais tendo suas práticas profissionais voltadas ao conteúdo, assunto e informação presentes nos suportes de registro do conhecimento.

Quanto ao Paradigma Pós-Custodial, Malheiro e Ribeiro (2011) afirmam que o mesmo possui caráter "informacional e científico - fomentado e intensificado pelo desenrolar acelerado da Era da Informação (datável, genericamente, a partir de 1945) em que estamos e, em particular, pela conjuntura internacional da Rede" (MALHEIRO; RIBEIRO, 2011, p. 13-14). Esse paradigma seria um contraponto em relação ao paradigma da custódia. Na perspectiva custodial, a guarda e preservação dos acervos estava ligada à razão de ser das bibliotecas, arquivos e museus. Na passagem para uma nova abordagem, essa função não tem o mesmo significado, mas ela não deixa de existir.

No Quadro 2, estão reunidos os principais traços do Paradigma Pós-Custodial, destacados por Malheiro e Ribeiro (2011).

Quadro 2 - Traços Essenciais do Paradigma Pós-Custodial.

\section{PARADIGMA PÓS-CUSTODIAL (Informacional e científico)}

Valorização da informação enquanto fenômeno humano e social, sendo a materialização em qualquer suporte um epifenômeno;

Constatação do incessante e natural dinamismo informacional, oposto ao "imobilismo" documental, traduzindo-se aquele trinômio criação-seleção natural versus acesso-uso, e o segundo, na antinomia efémero versus permanência;

Prioridade máxima dada ao acesso à informação, por todos em condições bem definidas e transparentes, pois só o acesso público justifica e legitima a custódia e a preservação;

Imperativo de indagar, compreender e explicar (conhecer) a informação social, através de modelos teóricos-científicos cada vez mais exigentes e eficazes, em vez do universo rudimentar e fechado da prática empírica composta por um conjunto uniforme e acríticos de modos/regras de fazer, de procedimentos só aparentemente "assépticos" ou neutrais de criação, classificação, ordenação e recuperação;

Alteração do atual quadro teórico-funcional da atividade disciplinar e profissional por uma postura diferente, sintonizada com o universo dinâmico das Ciências Sociais e empenhada na compreensão do social e do cultural, com óbvias implicações nos modelos formativos dos futuros profissionais da informação; 
Substituição da lógica instrumental, patente nas expressões "gestão de documentos" e "gestão da informação", pela lógica científico-compreensiva da informação na gestão, isto é, a informação social está implicada no processo de gestão de qualquer entidade ou organização.

Fonte: Malheiro e Ribeiro (2011, p. 59-60)

Pelos traços elencados, vemos como a função de custódia se ressignifica quando o acesso de conteúdos informacionais passa a ser uma prioridade das práticas dos profissionais da informação, pois a guarda e preservação da informação devem ser feitas com o objetivo de que a mesma venha ser acessada. Se colocarmos a memória sobre a égide desse novo paradigma, podemos dizer que o mesmo deverá ser aplicado a esta, ou seja, a guarda da memória só será legítima se realizada com o intuito de que possa ser disponibilizada e acessada de forma democrática.

O surgimento da Ciência da Informação estaria imbricado a um caminhar para uma abordagem pós-custodial e informacional, que se inicia na busca dos profissionais da informação por novas práticas, quando a organização, armazenamento, acesso, mediação e uso da informação passa a ser o ponto central de suas atividades.

Devido a relação próxima às disciplinas da Biblioteconomia, da Arquivologia e Museologia, a CI herda ainda alguns traços do Paradigma Custodial, dentre eles, o papel de preservação da memória e da história através dos registros do conhecimento. Para Malheiro e Ribeiro (2011, p. 72) a Ciência da Informação,

[...] congrega em si a herança disciplinar advinda de um tempo ou paradigma (custodial e patrimonialista), em que a preocupação central foi a de localizar, ordenar, descrever e recuperar documentos/objetos físicos, que interessava guardar e proteger como bens patrimoniais valiosos.

Nessa mesma perspectiva, Pinheiro (2005, p. 16) diz que o tema memória encontrase na raiz da $\mathrm{CI}$, pois a Documentação, sua antecessora, teria um de seus focos voltado ao "registro do conhecimento científico, a memória intelectual da civilização". O Traité de documentation de Otlet (1934) foi o marco fundador da Documentação e, nele, o objetivo de preservação da memória do conhecimento está implícito na ideia de preservação dos registros da informação. (OLIVEIRA; RODRIGUES, 2009)

Nesse sentido, é possível perceber que a transição entre os paradigmas (ainda não finalizada) não implica na ruptura total com as práticas de origem custodial relativas às áreas da Biblioteconomia, Arquivologia e Museologia, as quais contribuíram para o surgimento da CI e que hoje são consideradas correlatas à mesma (ARAÚJO, 2012). A mudança está justamente no foco dado a essas práticas, não mais o de restringir, mais o de disponibilizar a informação, a memória e o conhecimento.

Oliveira e Rodrigues (2011) indicam a existência de estudos sobre a memória na CI sob três principais perspectivas, a primeira delas, é a da memória humana, que reúne estudos focados na capacidade mental humana, de reter dados, informações e experiências. A segunda, seria a memória artificial, onde o foco dos estudos está na possibilidade de materialização da memória através de suportes como livros, documentos, dispositivos eletrônicos e digitais etc. E, em uma terceira perspectiva, estariam as pesquisas ligadas à memória social, aquela que se constrói socialmente e que pode ser percebida e estudada por meio dos registros informacionais.

Feita essa contextualização teórica e conceitual de entrelaçamento da memória e da informação na $\mathrm{CI}$, podemos refletir que, através de novas formas e significações, a memória continua atrelada às áreas da Biblioteconomia, da Arquivologia e da Museologia, pois a mesma veio como herança dessas áreas. Contudo, a forma como a CI se direciona a esse 
objeto de estudo, herdado das abordagens custodiais, encontra-se atrelado à uma nova abordagem, mais dinâmica, que enxerga esse objeto de maneira a conferir-lhe um caráter informacional, indo além do sentido da guarda e da preservação.

\section{CONSIDERAÇõES FINAIS}

Pelo exposto, é possível perceber as aproximações entre informação e memória, a partir das concepções relacionadas às esferas física, cognitiva e social. Evidenciar essas afinidades entre esses dois objetos de estudo, à luz dos paradigmas atrelados a CI sobre os quais discorremos ao longo do texto, nos auxilia na compreensão de como o tema memória pode ser explorado no referido campo científico.

As aproximações teóricas das perspectivas acerca da memória e da informação, apresentadas neste estudo, nos orientam para a ideia de que a memória tem sido inerente às práticas relacionadas aos campos da Biblioteconomia, Arquivologia e Museologia desde a Antiguidade. E que essa relação permanece presente ainda com o surgimento da Documentação e, posteriormente, da CI.

Vinda como herança das práticas custodiais, a memória chega à Ciência da Informação como um campo fértil e rico de estudos filosófico, histórico, sociológico e epistemológico. Exemplo disso, são os estudos em que a memória social é posta sob um olhar informacional, o que possibilita a abrangência de diversos tipos de pesquisas, a exemplo dos registros informacionais como forma de conhecer e ter acesso à memória de indivíduos, grupos, cidades, países, instituições dentre outros. Outro exemplo, é o estudo da capacidade dos suportes e das técnicas informacionais de preservação, acesso e difusão da memória.

Observa-se que, mesmo no contexto contemporâneo em que a informação é vista como elemento essencial para a sociedade, a memória encontra lugar no campo da $\mathrm{CI}$, que direciona seu foco aos processos e fluxos informacionais. Estudos e discussões sobre memória atravessam séculos, enquanto que a informação tem sido tema de debate próprio da modernidade. Nesse sentido, é interessante ver como informação e memória convergem em um campo científico como a CI, que é considerada uma área recente e pós-moderna.

A forma como a memória transita ao longo do tempo entre abordagens custodiais e pós-custodiais nos remete à reflexão de que a memória parece resistir às mudanças do tempo, cronológico e simbólico, como se ela fosse imortal. Halbwachs (1990) e Nora (1993) em suas reflexões, nos deixam com esse sentimento, de que a memória sempre será parte indissociável de uma sociedade, independentemente do tempo em que se encontra. A forma como a memória se adapta, se adequa e se ressignifica na concepção pós-custodial em que a CI se consolida, parece reafirmar os pensamentos desses autores, acerca da sacralização da memória, e que ela vive em um estado de eterno presente.

\section{REFERÊNCIAS}

ARAÚJO, C. A. A. Paradigma social nos estudos de usuários da informação: abordagem interacionista. Informação \& Sociedade: Estudos, João Pessoa, v.22, n.1, p.145-159, jan./abr. 2012.

. Arquivologia, biblioteconomia, museologia e ciência da informação: o diálogo possível. Brasília: Briquet de Lemos, 2014.

BAUMAN, Z. Modernidade Líquida. Rio de Janeiro: Jorge Zahar Editora, 2001.

BELKIN, N. J. Anomalous States of Knowledge as Basis for Information Retrieval. The Canadian Journal of Information Science, v. 5, p. 133-143, 1984. 
BELKIN, N. J.; ODDY, R.N.; BROOKS, H.M. ASK for Information Retrieval: Part I. Background and Theory. Journal of Documentation, v. 38, n. 2, p. 61-71, 1982.

BERGSON, H. Matéria e Memória. 4. ed. São Paulo: Martins Fontes, 2010.

BROOKES, B.C. The developing cognitive view in information science. In: INTERNATIONAL WORKSHOP ON THE COGNITIVE VIEWPOINT, p.195-203, 1977.

BUCKLAND, M. K. Information and Information Systems. New York, 1991.

CANDAU, J. Memória e Identidade. São Paulo: Contexto, 2012.

CAPURRO, R.; HJORLAND, B. O conceito de informação. Perspectivas em Ciência da Informação, Belo Horizonte, v.12, n.1, p.148-207, jan./abr. 2007. Disponível em:

<http://portaldeperiodicos.eci.ufmg.br/index.php/pci/article/view/54/47>. Acesso em: 23 nov. 2016

CAPURRO, R. Epistemologia e Ciência da informação. In: ENCONTRO NACIONAL DE PESQUISA EM CIÊNCIA DA INFORMAÇ̃̃O, 5, Belo Horizonte, 2003. Anais... Belo Horizonte: Escola de Ciência da informação da UFMG, 2003. Disponível em: < http://www.capurro.de/enancib_p.htm>. Acesso em: 25 nov. 2016

CASTELLS, M. A sociedade em rede. 11. ed. São Paulo: Paz e Terra, 2008.

GONZÁLEZ DE GÓMEZ, M. N. A Reinvenção Contemporânea da Informação: entre o material e o imaterial. Pesq. Bras. Ci. Inf., Brasília, v. 2, n. 1, p. 115-134, jan./dez. 2009. Disponível em: <http://repositorio.ibict.br/bitstream/123456789/116/1/GonzalezGomezTendencias2009.pdf >. Acesso em: 20 out. 2016.

HALBWACHS, Maurice. A Memória Coletiva. São Paulo: Edições Vértice, 1990.

LE GOFF, J. História e memória. Campinas, SP: Ed. da Unicamp, 2003.

MALHEIRO, A.; RIBEIRO, F. Paradigmas serviços e mediações em Ciência da Informação. Recife: Nectar, 2011.

MEIRELES, M. R. G.; CENDÓN, B. V. Aplicação prática dos processos de análise de conteúdo e de análise de citações em artigos relacionados às redes neurais artificiais. Inf. Inf., Londrina, v. 15, n. 2, p. 77-93, jul. /dez. 2010. Disponível em:

<http://www.uel.br/revistas/uel/index.php/informacao/article/view/4884>. Acesso em: 3 nov. 2016.

NORA, P. Entre memória e história: a problemática dos lugares. Projeto História, São Paulo, n.10, p. 728, dez. 1993.

OLIVEIRA, E. B.; RODRIGUES, G. M. O conceito de memória na Ciência da Informação: análise das teses e dissertações dos programas de pós-graduação no Brasil. Liinc em Revista, v.7, n.1, p. 311-328, mar. 2011. Disponível em: <http://repositorio.unb.br/bitstream/10482/8511/1/ARTIGO_ConceitoMemoriaCienciaInforma\%C3 \%A7\%C3\%A3o.pdf >. Acesso em: 13 nov. 2016.

As concepções de memória na Ciência da Informação no Brasil: estudo preliminar sobre a ocorrência do tema na produção científica. Ponto de Acesso, Salvador, v. 3, n. 3, p. 216-239, dez. 2009. Disponível em:

<https://portalseer.ufba.br/index.php/revistaici/article/view/3613/2745 >. Acesso em: 13 nov. 2016

OTLET, P. Traité de Documentation - Le livre sur le Livre - Théorie et Patique. Bruxeles: Editiones Mundaneum, 1934

PINHEIRO, L. V. Processo evolutivo e tendências contemporâneas da ciência da informação. Informação \& Sociedade: Estudos, João Pessoa, v. 15, n. 1, p. 13-48, jan./jun. 2005.

POLLAK, M. Memória e identidade social. Estudos históricos, Rio de Janeiro, v. 5, n. 10, p. 200-2012, 1992. 
ROBREDO, J. Organização dos documentos ou organização da informação: uma questão de escolha. In: SEMINÁRIO GESTÃO DA INFORMAÇÃO: DESAFIOS E SOLUÇÕES, Brasília: ACECO, Arquivo Nacional, Câmara dos Deputados, Conselho da Justiça Federal, Senado Federal e Universidade de Brasília. 2003.

SHANNON, C. E.; WEAVER, W. The Mathematical Theory of Communication. Urbana: University of Illinois Press, 1949.

WURMAN, R. S. Ansiedade de informação: como transformar informação em compreensão. São Paulo: Cultura, 1991.

Editores do artigo: Enrique Muriel-Torrado e Adilson Luiz Pinto 